\title{
Study on the Applied Translation under Functionalism Skopos Theory
}

\author{
Wei Wang \\ School of English Language and Culture, Xi'an Fanyi University, Xi’an, Shaanxi, 710105
}

Keywords: Functionalism Skopos theory; applied translation; study

\begin{abstract}
This paper first introduces the functionalist translation theory of Germany, and then argues that functionalism translation theory is also applicable to literary translation and the translator's creativity from the Skopos Theory and equivalence of literary translation. The application of three basic principles of functionalism Skopos translation theory in literary translation is described in this paper.
\end{abstract}

\section{Introduction}

With the continuous expansion and enrichment of literature, functionalist translation theory has become an indispensable part of literature. In the translation of English literary works, functionalist translation theory is also particularly important [1]. The theory of translation is easy to understand. It is actually another writing of the original text. The specific point of functionalist translators in the process of interpreting literary works is to carry out their own work on foreign literary works. Analysis of deconstruction and cultural transfer, and then through the translator's understanding of foreign literary works and on the basis of cultural background to further re-structure, so as to be able to form a perfect text.

\section{Functionalism Skopos Theory}

Functionalist translation theory is a conceptual concept segment that consists of a natural segment or multiple natural segments. It also has a rhetorical function with a clear theme, so that the rhetorical functions of translation theories can be presented again and can be used in the same form. To find the equivalent of a function, an equivalent translation like this is called functionalist translation. The premise of the translation of literary works is to have the equivalent of rhetorical functions, and must also comply with the relevant translation norms. According to different literary works, the purpose of functionalism translation is also very different. In the functionalist translation theory of literary works, it finally needs to emphasize the rhetorical form of the literary works and the functional equivalent of the literary works [2]. Therefore, the two words of rhetoric are regarded as forms and means, and the function is the two words are regarded as the purpose achieved in the process of rhetoric or the result produced. The rhetoric of functionalist translation theory consists of two parts: the rhetoric in each paragraph of the literary concept and the rhetoric in each sentence [2]. The functional translation theory in literary works is mainly to understand the role of translation theory in understanding the theory of schemata in practice. For a variety of special structures and universal structure recognition schemas, if more abundant and more specific than before, then the practical ability and research in translation are even more intense. These are the translators in literary works. The necessary prerequisite for the formation of schema text. Functionalist translation theory also emphasizes the process of functionalist translation in literary works. It is in fact a process of reasoning, in which the basic structure of logical reasoning is the causal chain, which makes reasonable use of information already known. For some cultural works, such as the use of culture, the use of language, and the formation of language and other non-language elements such as linguistic context formed by the rhetoric function to further make a reasonable judgment, so that it can produce a more correct timing.

Understand the understanding of the subject of the concept section. Among them, the most important thing is to divide the literary works in detail and divide them into conceptual paragraphs; 
then, to study the conceptual ideology of the divided conceptual sections, and to find out the connection symbols of the conceptual paragraphs; The causal chain of the conceptual segment divided into is firmly grasped, grasping the functional orientation of the literary language at any time, and thus fundamentally understanding all the content of the divided conceptual segment. Schema research method. In simple terms, the schema theory can be used to conduct detailed research and analysis on the cognitive patterns of all the different structures of the original and target sentences in literary works [3]. For example, comparing SVO sentences in other foreign languages and the structure diagrams of sentences such as various passive sentences with the structure of the target sentences can be used to discover and understand the original sentence and the target sentence. The method and law of translation. According to cognitive schema theory, it should be noted that the internal semantics and structure of the linguistic structure of the literary works, such as the subject, the predicate, the guest, and the complement, should be specifically analyzed so that the function of the sentence can be correctly grasped. Functional classification method. Functional classification linguistics in functional translation theory divides the rhetoric function of English into five categories: definition function, description function, classification function, instruction function, and statement function. Each rhetorical function of these five categories of rhetorical functions is divided into numerous small rhetorical functions. These functions and the Chinese language of literary works can be used to explore the laws of translation theory.

\section{The Application of Three Principles of Functionalism Skopos Translation Theory in Literary Translation}

Throughout the history of literary translation, the principle of purpose has been used to manipulate translation. For example, in 1853, William Chalmers Burns translated English the 17th century narrator John Bunyan's The Pilgrim's Progress into Chinese. His purpose was to infiltrate Western Christian ideas into the Chinese social ideology of the time. In the same way, in 1909, Lu Xun and Zhou Zuoren compiled the Collection of Foreign Fiction. Their purpose was to "transfer sexuality and transform society [4].”

In functionalist translation theory, the principle of coherence is more important than the principle of loyalty. The so-called coherence principle is that the translation content must be consistent to ensure that the target reader can read and understand the translation. This is also a very important and widely used principle in literary translation. It is expressed in translation techniques (1) for free translation or paraphrase, especially for the translation of allusions rich in cultural significance; (2) and the culture and language of the target language. Habits remain consistent. For example: The heart is more than a dry one, and the illness is like a victory for three points. "Dream of the Red Chamber "She had more chambers in her heart than the martyred Bi Gan, and suffer a tithe more pain in it than the beautiful Xi Shi. (Hawkes translation) She looked more sensitive than Bi Gan1, more delicate than Xi Shi2.Notes: 1 A prince noted for his great intelligence at the end of the Sang Dynasty. 2. A famous beauty of the ancient kingdom of yue. Comparing the translation of Yang Xianyi and Mr. Hawkes, we can see that in the Chinese allusion When translating the words "Biqian and Xizi”, they adopted different methods. Yang Xianyi and his wife used literal translation to convey the original text. Mr. Hawkes used free translation to better ensure the coherence and smoothness of the translation. This allows the target readers to read continuously without interruption, thus increasing the readability of the translation. Here, we are not criticizing Yang's translation as being not as good as Huo's translation. I just want to show that the principle of coherence is widely used in a large number of literary translations. Liu Yudao said: "This is not true. The people who work in person, things in heaven." "I wouldn't say that, 'said Grannie Liu. 'Man proposes, God disposes.' (Hawkes translation) "Don't be so sure," said Granny Liu, "Man proposes, Heaven disposes." (In the above example, the words "recruiting things to people and accomplishing things to the heavens", Yang Xianyi and his wife still use the literal translation method to translate the words "Heaven", which is rich in Chinese cultural connotations, into "Heaven," and Hawkes. Mr. translates it into the word "God" with Western characteristics. Hawkes's "God", which is natural 
for Western readers, is entirely due to the consideration of the target readers because he believes that the translator is obliged to be faithful to the original author, the source text, and the target reader. (Hawkes, 1977: 20) And looking at his translations, we can see that he seems to care more about loyal readers. Therefore, in Hawkes's translation, he considers for the target reader and tries to be consistent with the target language environment and habits. This makes his translation more readable and easier for the target reader to like and accept. 3.3 The application of loyalty principle in literary translation The translation of the main principles of translation should be followed by the principle of translating the principle of the principle of coherence, followed by the principle of coherence. On this basis, it is necessary to follow the principle of loyalty. The so-called loyalty principle is that the translation should be as faithful as possible to the original text, which is also the traditional concept of "faithfulness, reciprocity." In literary translation, this viewpoint has occupied an important position from ancient to modern times. Therefore, there are many examples of applications of the loyalty principle. In the above example, we can see that the translation of Yang Xianyi's couple is more faithful to the original text, trying to copy the original content, language form, stylistic style and so on.

The literary works show the mood and emotion of the author when he writes through aesthetic values. These aesthetic values can better attract readers' attention. In addition, functionalist translation theory can also better reflect the overall rhythm of literary works. By analyzing the overall rhythm of literary works, we can better judge whether these literary works have aesthetic value, so as to better perform these literary works. spread. An important way to judge whether literary works have aesthetic value is to judge whether the literary works are consistent with the original after translation. People usually like to vocally read aloud when they appreciate and read literary works, and they only read interesting literary works. If a literary work is more attractive in terms of rhythm and rhythm, then First of all, it will give people a sense of aesthetic pleasure to enjoy literary works, which of course is also the literary creation and translation of the linguistic language has a relatively high demand.

As with other translations, the translation of literary works is actually a cross-cultural communication activity. Eastern and Western cultures have common features and their own characteristics. The artistic characteristics of functionalist translation theory are an important means to express the characteristics of literary translation. The most common artistic methods in literary translation are expression methods, and many literatures. The works use a large number of expression techniques such as lyrics, puns, or metaphors. These expressions make the language beautiful, rich and colorful, and diverse in form. It also makes literary translation more distinctive. It is these artistic techniques that have enabled the literary translation of the aesthetic value has been further demonstrated. In addition, with the rapid development of the global economy, exchanges between countries are more and more frequent, and literary works are also an important means of communication between countries [5]. Through the artistic characteristics of literary translation, we can better understand and Learn about foreign cultures, learn from each other, learn from their excellent culture, and apply these outstanding cultures to China's cultural creation.

\section{Conclusion}

Functionalist translation theory is a pragmatic representation of translation theory and plays an extremely important role. We must realize that translation is not stereotyped, culture has its rich connotations, and a certain method can be completely solved. We should more specifically analyze specific situations and seek ways to continuously solve problems that cannot be solved in translation.

\section{Acknowledgements}

Title of the project: This thesis is a key project of Xi'an Fanyi University and the project number: 12A04. It's also the outcome of the college-level research team "English Language service and regional economy cooperative development”, and the research team number: XFU17KYTDC09. 


\section{References}

[1] Baker, Mona. Routledge Encyclopedia of Translation Studies [M]. Shanghai: Shanghai Foreign Language Education Press, 2004.

[2] Gentzler, Edwin. Contemporary Translation Theories [M]. Shanghai: Shanghai Foreign Language Education Press, 2004.

[3] Hawkes, D. The Story of the Stone (vol.1) London: Penguin Books, 1973.

[4] Hawkes, D. The Story of the Stone (vol.2). London: Penguin Books, 1977: 20.

[5] Nord, Christine. Translating as a Purposeful Activity: Functional Approaches Explained [M]. Shanghai: Shanghai Foreign Language Education Press, 2001. 